\title{
Biotechnical system with use of telemedicine for diagnostics of movements of the person
}

\author{
David Khachaturyan \\ University,Deparment of Industrial and Medical \\ Electronics \\ National Research Tomsk Polytechnic \\ Tomsk, Russia \\ david.khachaturyan@yahoo.com \\ Jacov Pekker \\ Medical and Biological Cybernetics with a course in \\ Medical Informatics \\ Siberian State Medical University \\ Deparment of Industrial and Medical Electronics \\ National Research Tomsk Polytechnic University \\ Tomsk Russia \\ pekker@ssmu.ru
}

\begin{abstract}
The system of detection of pathologies and diagnostics of movements of the person, on means of telemedicine is developed. The system integrating in itself virtual surroundings of patient and capture of motion is worked out. The technique gives the chance is removed to estimate a functional condition of a vestibular mechanism, carrying out a research of influence of the virtual environment on balance of the person.
\end{abstract}

Keywords — biotechnical system, telemedicine, virtual reality, pastoralia tests, the vestibular mechanism.

\section{INTRODUCTION}

The system development allowing far off carrying out researches on means of the virtual environment integrated with the captures the movement system of the video. In the entire countries of the world hi-tech medic are is possible only in large medical centers and specialized institutes.

Problems of health care consist in deficiency of specialist's doctors, medical personnel remoteness of country towns and villages from the medical centers and often in the inefficient organization of the emergency medical care to the population of the remote areas. Achievements of telecommunication and information technologies eliminate need for physical presence of the expert on the place. Term "telemedicine" entered by $\mathrm{R}$. Mark in 1974 from other data unites the great number of the telecommunication and informative methods applied in a health protection and also their various clinical applications.

Motive disorders and pathologies of vestibular vehicle are widespread enough now. There is a problem of early exposure of violations and timely treatment frequently from the remoteness of the specialized centers competent specialists and effective equipment[2].

As many departments of central nervous system take part in a management motions the results of analysis of motions can be drawn on for diagnostics. Registration of spatial and temporary characteristics of movements gives the chance to estimate extent of motive frustration at various

\author{
Ivan Tolmachev \\ Deparment of Industrial and Medical Electronics \\ National Research Tomsk Polytechnic University \\ Biological Cybernetics with a course in Medical \\ Siberian State Medical University, Medical and \\ Informatics \\ Tomsk, Russia \\ ivantolm@mail.ru \\ Konstantin Brazovskii \\ Biological Cybernetics with a course in Medical \\ Informatics \\ Siberian State Medical University, Medical and \\ Toms, Russia \\ bks_2005@mail.ru
}

diseases the course of restoration of motive functions to offer effective methods of motive rehabilitation.

\section{STUSY DESING}

A virtual three-dimensional environment is worked out the model of man is integrated. By means of the chosen points of body it is possible to diagnose and estimate the degree of violations of motions of man. This method allows to conduct researches in home terms, at presence of necessary facilities.

Necessary acquisition for realization of research:

-personal computer and with access in the internet.

-glass of virtual reality.

-appliance video capture of motion.

A method allows real-time to involve the competent specialists of being in the different points of country or world for the receipt of exact description of pathology of consultations and methods of treatment. Fig. 1.

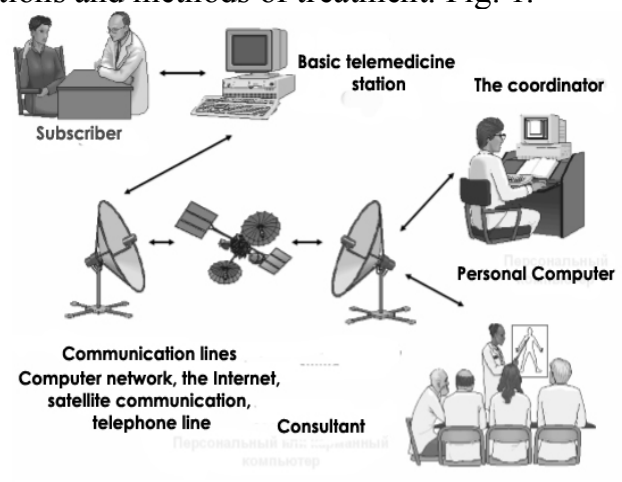

Fig 1. Scheme of remote diagnostics of the movement of the person.

Sample scenario of diagnostics and assessment of motion is a human.

1) A Doctor-subscriber, or user visits by means of the internet the specialized server and in his database places information about itself (registration) and hospital of this 
patient chart in obedience to set by the creators of server to the form[5].

2) A Doctor-consultant studies the presented hospital chart, appoints a date and time of realization of remote research and notifies a user. To bring in data in the specialized database, opening access of anamnesis of patient for other to the competent doctors.

3 ) In the appointed date, by means of the program, takes place researches. Consultants supervises realizations of research in on-line mode if necessary to eat possibility to research to connect the doctors of neurologists [2].

The study was conducted in two groups: the first, reference group, consisted of 9 healthy subjects; the second group was comprised of 9 patients with minor neurological deficits and negative Romberg's test.

Functional postural tests were used along with a videobased markless motion capture technique. The protocol included Romberg's test that followed by the Balance Evaluation Systems Test (miniBESTtest,). The Cartesian coordinates of the featured points were captured by means of Microsoft Kinect hardware. The "Brekel Kinect free" software was used to preprocess and collect raw data [4].

Finally, our new numerical distance-based criterion was calculated. After that the criterion was compared against the scores of the BESTtest and known indexes such as average speed and patented Equilibrium Function Quality (EFQ). Statistical hypotheses were tested by Mann-Whitney U nonparametric test (MW test), Spearmen rank correlation was used as well.

This technology allows registering the threedimensional coordinates of position 20 standard points on the body of patient with frequency a 15 counting out in a second [6].

\section{METHODS AND MATERIALS}

The theoretical details of the criterion were published in. Briefly, the data processing pipeline can be given as follow Fig. 2.

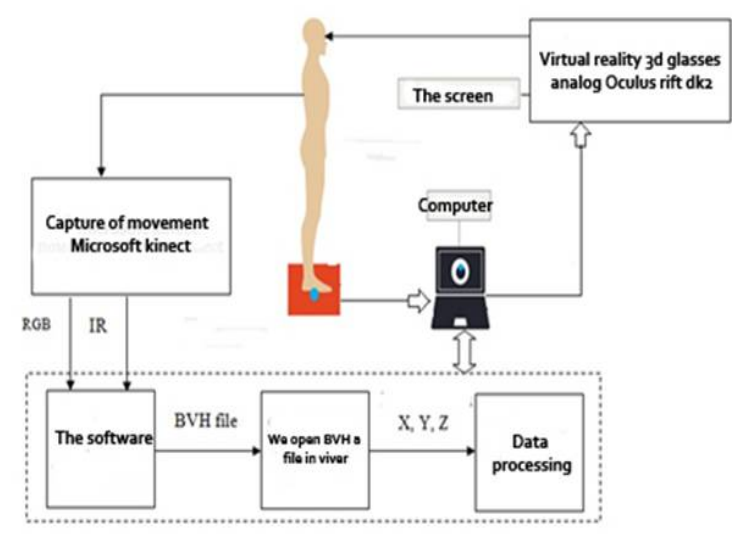

Fig. 2. Algorithm video-based markless motion capture
1. First of all, time series vectors $\boldsymbol{x}(t), t=0, \mathrm{~T}$ have to be measured for each subject during the period of time with length $T$. Here $\boldsymbol{x}(t)$ is a multidimensional value, for example, the $3 \mathrm{D}$ coordinates of a certain point.

2. The whole interval $[0, \mathrm{~T}]$ then is divided into $k$ fragments with length $\Delta \mathrm{T}$. The average values $\boldsymbol{x}_{j}, j=0, k$ are calculated inside the $[t, t+\Delta \mathrm{T}]$ intervals (1):

$$
x_{j}=\frac{1}{n} \sum_{i=1}^{n} x\left(t_{i}\right)
$$

where $\mathrm{n}$ is a number of the measured values inside the interval.

3. The averaged values are normalized (2) and put into the $\mathrm{N} \times \mathrm{k}$ state matrix $\mathrm{S}, \mathrm{N}$ is a number of subjects in a certain group [3].

$$
\begin{aligned}
& \mathrm{x}_{\mathrm{j}, \text { norm }}=\frac{\mathrm{x}_{\mathrm{j}}-\mathrm{x}_{\text {min }}}{\mathrm{x}_{\text {max }}-\mathrm{x}_{\text {min }}}, \mathrm{j}=1, \mathrm{k} \\
& \mathrm{x}_{\text {min }}=\min _{\mathrm{j}=1, \mathrm{k}}\left\{\mathrm{x}_{\mathrm{j}}\right\}, \quad \mathrm{x}_{\max }=\max _{\mathrm{j}=1, \mathrm{k}}\left\{\mathrm{x}_{\mathrm{j}}\right\}
\end{aligned}
$$

4. All averaged and normalized values of the healthy subjects $\mathbf{x}_{\mathrm{v}}$ are merged into the reference matrix $\mathbf{S}_{0}$ with size $\mathrm{N}_{0}$, and then a covariance matrix $\mathbf{C}$ with $\mathrm{k} \times \mathrm{k}$ size is calculated.

5. Finally, the distance-based dimensionless criterion Id is calculated (3), using the averaged and normalized values $\mathbf{x}_{u}$ obtained from the patients.

$$
\operatorname{Id}\left(\mathrm{x}_{\mathrm{u}}\right)=\frac{1}{2 \mathrm{k}}\left[\frac{1}{\mathrm{~N}_{0}} \sum_{\mathrm{v}=1}^{\mathrm{N}_{0}}\left(\mathrm{x}_{\mathrm{u}}-\mathrm{x}_{\mathrm{v}}\right) \mathrm{C}^{-1}\left(\mathrm{x}_{\mathrm{u}}-\mathrm{x}_{\mathrm{v}}\right)\right]
$$

where $\mathbf{x}_{\mathrm{v}}$ are the reference vectors from the reference group, and $\mathbf{x}_{\mathrm{u}}$ are the test vector obtained from a certain patient, $\mathbf{C}^{-1}$ is an inverse covariance matrix. In other words, our criterion is the averaged squared Mahalanobis distance between the certain vector and all vectors from the reference set [3].

Also we used EFQ test which is based on a vector statokinesigram and includes calculation of COP's velocity at each moment of time. After that a cumulative distribution function of the velocity distribution was approximated. The actual value of EFQ is relative area under the cumulative curve which is given as a percentage [4].

Usually, the conventional methods are able to evaluate movement of a single point (centre of pressure for example) only. In contrast, the Id is not limited by the dimension of the measured vectors and almost any reasonable length is appropriate. In order to make the developed criterion comparable to the common ones, a point corresponding to the center of mass was chosen. Vertical displacement ( $\mathrm{z}$ coordinate) was omitted. The data were recorded during Romberg's test with 15 samples/second rate and estimated spatial resolution about one millimetre. The overall period of time was $\mathrm{T}=10 \mathrm{sec}, \Delta \mathrm{T}=2 \mathrm{sec}, \mathrm{n}=30$ 
TABLE 1. INDIVIDUAL PARAMETERS FROM THE STUDIED SUBJECTS

\begin{tabular}{|c|c|c|c|c|}
\hline SUBJE & \begin{tabular}{|l|} 
MiniBEST \\
TEST \\
SCORES
\end{tabular} & \begin{tabular}{|l|} 
AVERAGE \\
SPEED \\
$M e \quad[Q 0,25-Q 0,75]$ \\
m/sec
\end{tabular} & EFQ, \% & ID \\
\hline $\mathrm{R} 1$ & 27 & $\begin{array}{cc}0,103 \\
0,159]\end{array}$ & 81,34 & 1,63 \\
\hline $\mathrm{R} 2$ & 28 & $\mid \begin{array}{c}0,015 \\
0,021]\end{array}$ & 73,83 & 1,37 \\
\hline R3 & 28 & $\begin{array}{cc}0,057 \\
0,096]\end{array}$ & 85,23 & 1,21 \\
\hline R4 & 28 & $\begin{array}{c}0,013 \\
0,021]\end{array} \quad[0,008$ & 81,01 & 1,15 \\
\hline R5 & 27 & $\begin{array}{cc}0,034 \\
0,063]\end{array}$ & 83,89 & 1,30 \\
\hline R6 & 28 & $\mid \begin{array}{c}0,021 \\
0,032]\end{array}$ & 76,04 & 1,35 \\
\hline R7 & 27 & $\begin{array}{r}0,040 \quad[0,021- \\
0,082]\end{array}$ & 83,36 & 1,37 \\
\hline R8 & 27 & $\begin{array}{c}0,057 \quad[0,028- \\
0,100]\end{array}$ & 84,36 & 1,46 \\
\hline R9 & 27 & $\begin{array}{c}0,058 \quad[0,030- \\
0,103]\end{array}$ & 82,95 & 1,66 \\
\hline P1 & 13 & $\begin{array}{c}0,083 \\
0,164]\end{array}$ & 93,62 & 6,97 \\
\hline P2 & 11 & $\begin{array}{c}0,015 \quad[0,010- \\
0,022]\end{array}$ & 91,21 & 7,52 \\
\hline P3 & 28 & $\begin{array}{c}0,015 \\
0,022]\end{array}$ & 91,01 & 3,07 \\
\hline P4 & 28 & $\begin{array}{c}0,024 \\
0,058]\end{array}$ & 86,58 & 9,72 \\
\hline P5 & 15 & $\begin{array}{c}0,040 \quad[0,020- \\
0,060]\end{array}$ & 76,51 & 2,33 \\
\hline P6 & 28 & $\begin{array}{c}0,022 \quad[0,012- \\
0,041]\end{array}$ & 93,86 & 5,23 \\
\hline P7 & 26 & $\begin{array}{c}0,030 \\
0,046]\end{array}$ & 67,65 & 2,82 \\
\hline P8 & 28 & $\begin{array}{c}0,012 \quad[0,008- \\
0,020]\end{array}$ & 78,19 & 2,65 \\
\hline
\end{tabular}

TABLE 1, cont.

\begin{tabular}{|c|c|cc|c|c|}
\hline P9 & 28 & 0,020 & {$[0,011-$} & 82,55 & 3,46 \\
\hline $\begin{array}{c}\text { MW } \\
\text { test } \\
\text { Ref vs Pat }\end{array}$ & $\mathrm{p}=0,43$ & $\mathrm{p}=0,54$ & $\mathrm{p}=0,38$ & $\mathrm{p}<0,001$ \\
\hline
\end{tabular}

\section{RESULTS}

The individual calculated parameters are given in Table 1. The subjects R1-R9 form the reference group (Ref) and P1-P9 are in the group of patients (Pat). The average speed is given as a median and quartiles because this parameter does not fit the normal distribution.

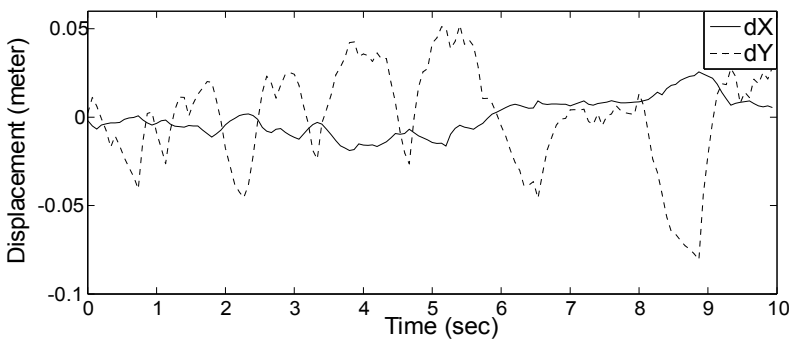
R2.

Fig. 3. The displacements of the selected point for the healthy subject

Despite the fact that all patients were Romberg's negative, three of them had the miniBESTtest scores from 11 to 15 . Nevertheless, the difference between two groups (reference and patients) is not statistically significant.

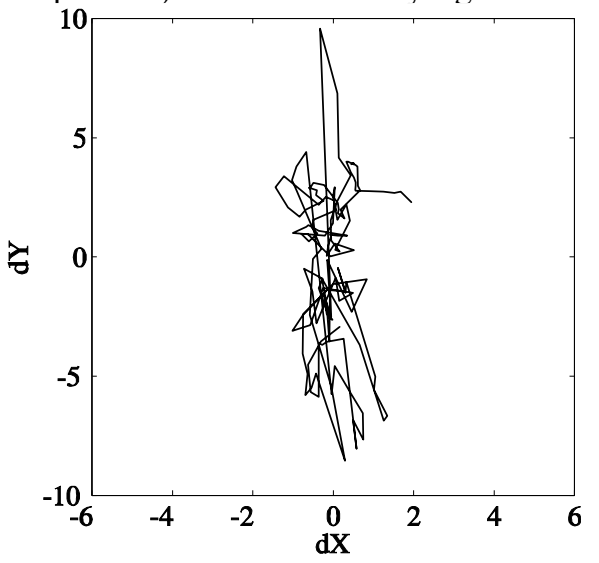

Fig. 4. Scatterogram of the selected point for the healthy subject R2. 


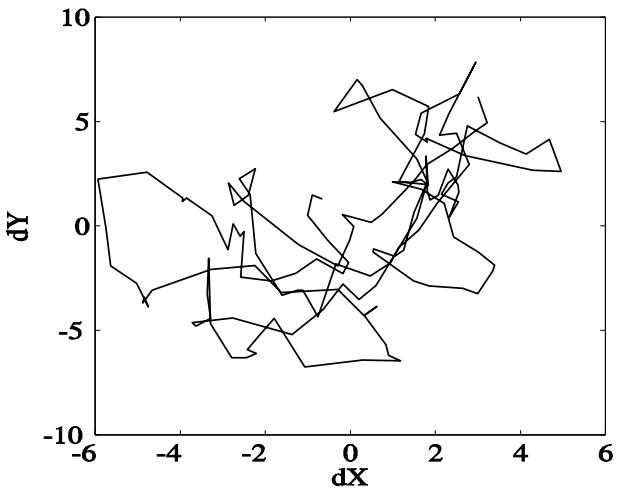
P1.

Fig. 5. The scatterogram of the selected point for the healthy patient

The average speed and EFQ also have practically the same values in both groups, whereas the distance-based criterion Id substantially varies between groups. What is more important is that all these parameters are not correlated (Spearmen $\mathrm{R}$ absolute values are less than 0,33 with $\mathrm{p}>0,15)$.

The example of the raw data ( $\mathrm{X}$ and $\mathrm{Y}$ coordinates of the selected point against time and its scattergram) is plotted in Fig. 3. The displacements are within the $10 \mathrm{~mm}$ range, and scattergrams have no signs of imbalance. The cumulative percentages related to the EFQ index are shown in Fig. 4. The cumulative distribution function of speed of the point was approximated by means of the empirical distribution step function.

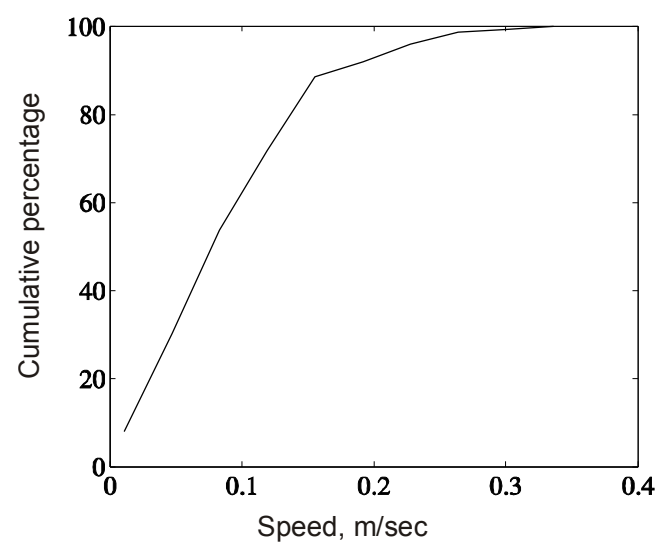

Fig. 6. The cumulative percent of speed of the selected point for the healthy subject R2.

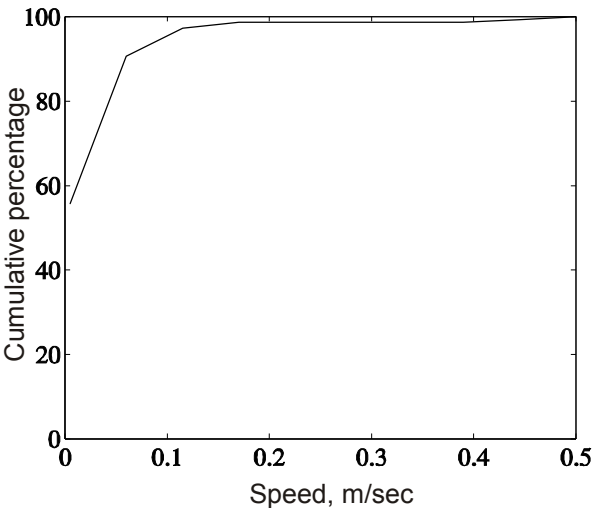

Fig. 7. The cumulative percent of speed of the selected point for the healthy patient $\mathrm{P} 1$.

The simplest way to explain the featured properties of our distance-based criterion Id is to represent the subjects, which involved in the study as a set of point in the 3D space of per-coordinate components Idx, Idy, Idz Fig. 5. Note, that the scales of axis are different and the Idx, Idy, Idz are the square root components of Id. It is clear that the reference group is quite compact, it members form one distinguishable cluster, while the patients are spread at a quite long distance from the reference group. This finding, on the one hand, highlights an inhomogeneity of the patient's group. On the other hand, the location of the certain patient may be considered either as an individual characteristic or as a pathological sign.

\section{CONCLUSION}

A new approach to acquire and process data of postural tests has been proposed and proved to be sensitive under normal gravity conditions. The method takes into account small variations of the trajectory linked to individual physiological features of the vestibular system. A data gathering procedure does not involve the exact value of gravity. The main advantages of the approach are outstanding simplicity and low cost of hardware along with a high level of sensitivity. The specificity of the developed criterion towards the certain vestibular pathology is a discussable point and should be further investigated.

\section{REFERENCES}

[1] S. Sliva. Domestic computer stabilografiya "technological level", functionality and scopes. Meditsinskaya Tekhnika magazine. the issue 1, February 2005.

[2] Ablaza V., Fisher J. Telemedicine and wound care management Home Care Provid,vol.3 , pp.206-213,1998

[3] Brazovsky K. S. Computational approach to assess postural tests under microgravity conditions "MATEC Web of Conferences",vol. 48, Space Engineering “IV Russian Forum for Young Scientists with International Participation”, Tomsk, Russia pp 4-65,April 2016

[4] V.A. Fokin, Statistic data simulation at estimation of biological system state. Bulletin of the Tomsk Polytechnic University, Tomsk, vol. 311, № 5 , pp. 120-123, 2007

[5] A. Vladzimirsky, S. Loboda" the General principles of biotelemetric system for employees of services of rescue",Specialized medical care to urban population. Mater.nauch, pp. 7-9,Donetsk.1998. 
[6] D. Khachaturian Assessment of functional conditions of the person in parameters of the movement,"Collection of works VI of the AllRussian scientific and practical conference of students, graduate students and young scientists",Nondestructive control: electronic instrument making, technologies, safety , pp.230-235,Tomsk, 2015. 